\title{
Modules to enhance smart lighting education
}

Robert Bunch, Charles Joenathan, Kenneth Connor, Mohamed Chouikha

Robert M. Bunch, Charles Joenathan, Kenneth Connor, Mohamed Chouikha, "Modules to enhance smart lighting education," Proc. SPIE 8481, Optics Education and Outreach II, 84810B (15 October 2012); doi: 10.1117/12.928201

EDent: SPIE Optical Engineering + Applications, 2012, San Diego, California, United States 


\title{
Modules to enhance smart lighting education
}

\author{
Robert M. Bunch*a, Charles Joenathan ${ }^{\mathrm{a}}$, Kenneth Connor $^{\mathrm{b}}$, Mohamed Chouikha $^{\mathrm{c}}$ \\ ${ }^{\mathrm{a}}$ Department of Physics and Optical Engineering, Rose-Hulman Institute of Technology, 5500 \\ Wabash Avenue, Terre Haute, IN, USA 47803-0345; 'bmart Lighting Engineering Research Center, \\ Rensselaer Polytechnic Institute, 110 Eighth Street, Troy, NY USA 12180; ${ }^{c}$ Department of Electrical \\ and Computer Engineering, Howard University 2400 Sixth Street, NW, Washington, DC USA
}

20059

\begin{abstract}
Over the past several years there has been a rapid advancement in solid state lighting applications brought on by the development of high efficiency light emitting diodes. Development of lighting devices, systems and products that meet the demands of the future lighting marketplace requires workers from many disciplines including engineers, scientists, designers and architects. The National Science Foundation has recognized this fact and established the Smart Lighting Engineering Research Center that promotes research leading to smart lighting systems, partners with industry to enhance innovation and educates a diverse, world-class workforce. The lead institution is Rensselaer Polytechnic Institute with core partners Boston University and The University of New Mexico. Outreach partners include Howard University, Morgan State University, and Rose-Hulman Institute of Technology. Because of the multidisciplinary nature of advanced smart lighting systems workers often have little or no formal education in basic optics, lighting and illumination. This paper describes the initial stages of the development of self-contained and universally applicable educational modules that target essential optics topics needed for lighting applications. The modules are intended to be easily incorporated into new and existing courses by a variety of educators and/or to be used in a series of stand-alone, asynchronous training exercises by new graduate students. The ultimate goal of this effort is to produce resources such as video lectures, video presentations of students-teaching-students, classroom activities, assessment tools, student research projects and laboratories integrated into learning modules. Sample modules and resources will be highlighted. Other outreach activities such as plans for coursework, undergraduate research, design projects, and high school enrichment programs will be discussed.
\end{abstract}

Keywords: Optics education, Lighting education, Course modules

\section{INTRODUCTION}

The Smart Lighting Engineering Research Center (ERC) was created in 2008 at Rensselaer Polytechnic Institute with an overarching goal of developing new technologies and applications that will change the way society uses lighting. ${ }^{1}$ To achieve this goal it was quickly recognized that a broad array of academic disciplines would be involved and that the knowledge and skills required for researchers and workers would be multidisciplinary. Since part of the mission of the center is to "Educate a diverse, world-class workforce that will be needed to grow the business of Smart Lighting," educational programs must also be multidisciplinary and must contain both engineering and illumination content. ${ }^{1}$ Specifically, the educational goals for the center include: 1) Provide basic education required by new Smart Lighting industry, 2) Prepare new grad students for center research, and 3) Enhance existing undergraduate and graduate courses exploiting the broad applicability of Smart Lighting to photonics, optics, controls, communications, economics, electronics, etc. and stimulate interest in Smart Lighting. Achieving these goals requires developing curriculum content and course materials. This paper summarizes the Smart Lighting Engineering Research Center educational and outreach programs, describes how optics and optical engineering topics are incorporated, and provides an example of a modular course development in non-imaging optics.

*bunch@rose-hulman.edu; phone 812 877-8306; fax 812 877-8023; www.rose-hulman.edu

Optics Education and Outreach II, edited by G. Groot Gregory, Proc. of SPIE Vol. 8481

84810B · (C) 2012 SPIE · CCC code: 0277-786/12/\$18 · doi: 10.1117/12.928201 


\section{CURRICULUM AND MODULE CONCEPT}

\section{1 "Illumineer" curriculum}

The need of more lighting and illumination education for engineering students has been a topic of discussion for a number of years. ${ }^{2-4}$ Using this knowledge as background and driven by the needs of the ERC Industry partners as aggressively articulated by the Industrial Advisory Board, the Smart Lighting ERC faculty compiled a list of topics and desired skills needed for students to perform research in the center's laboratories and to become successful engineers and employees in a new Smart Lighting commercial enterprise. This multidisciplinary list of knowledge and required specific skills was categorized and formed into the basic components of what is termed an "Illumineer" curriculum seen in Fig. 1.

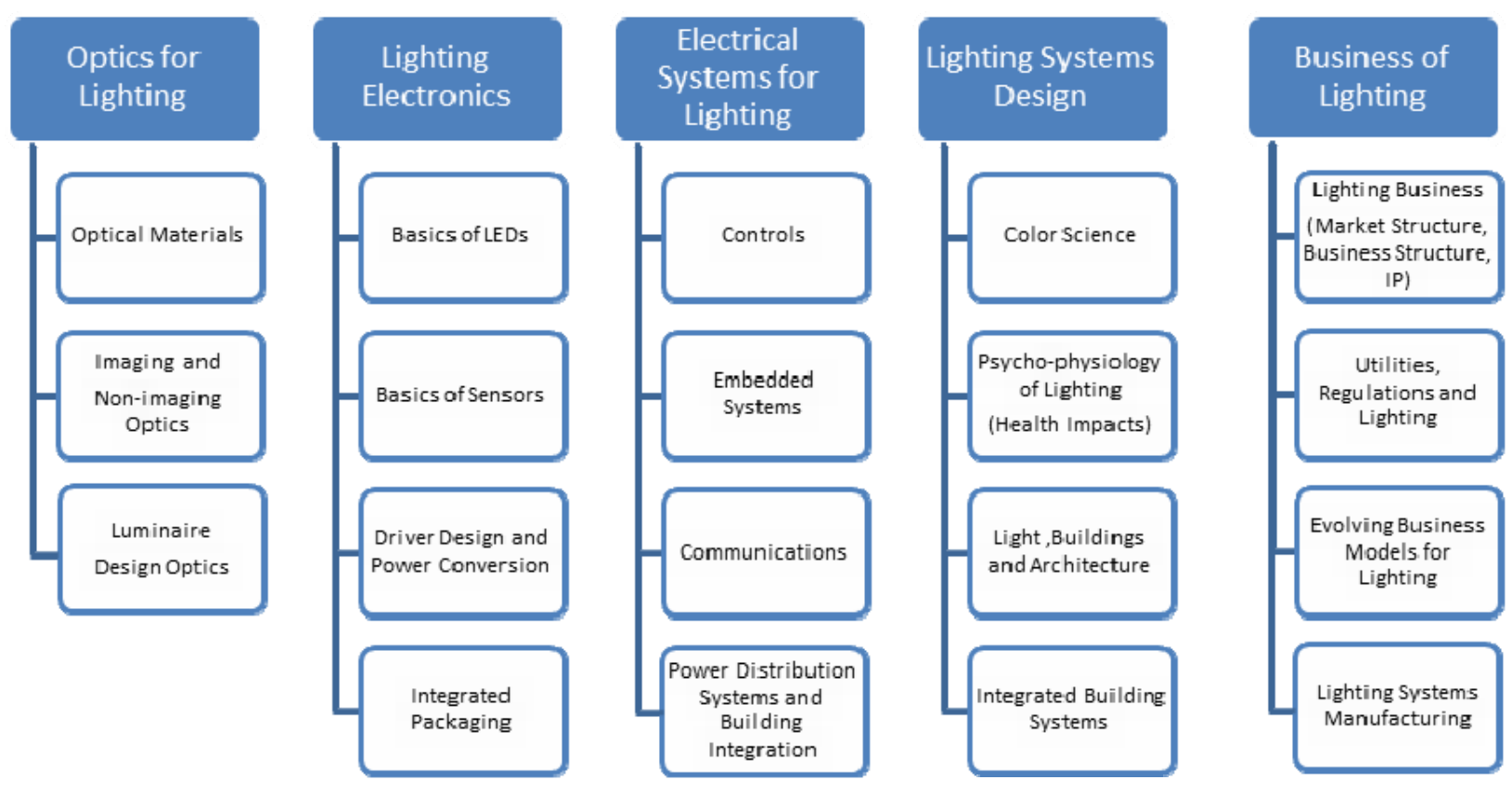

Figure 1. The "Illumineer" curriculum matrix showing topics for educational modules organized around major themes.

Students and faculty from several traditional disciplines, including electrical engineering, physics, mechanical engineering, optical engineering, chemical engineering, materials science and engineering, architecture, health sciences, management, and economics are participants in the Smart Lighting ERC. In fact, topics from each of these disciplines are represented in one or more of the blocks in the curriculum matrix. This curriculum emphasizes topics that will provide a sufficient breadth of lighting and illumination knowledge for a student while they are gaining depth in a particular discipline creating an educational experience to prepare the kind of "T-Shaped" people popularized by Tim Brown of IDEO. ${ }^{5}$

\subsection{Educational module concept and motivation}

We have chosen to organize this curricular content through the use of educational or learning modules. Each module is designed to be used by an instructor as part of a conventional course, by a student (graduate or undergraduate) as a standalone learning activity, or as a mixture of the two approaches. The materials can be in a variety of forms including structured activities, recorded lectures, statement of required background, learning objectives and activities (experiments, homework, quizzes), bill of required materials and facilities for experiments, course notes and other reading, and activity guides. 
The use of modules in higher education has been shown to be effective for motivating student interest in a particular subject. $^{6}$ As an example, recently developed courses using classroom modules for undergraduates studying nanotechnology showed that modular instruction positively influenced student's attitude toward the courses. ${ }^{7}$ Modular approaches have also been used effectively for optics outreach at the K-12 level. The hands-on-optics (HOO) program is an excellent example of the use of modules for outreach education targeting middle school students. ${ }^{8-10}$

Modules are convenient for instructors providing them with a package of materials available for incorporation into a course, learning activity or outreach program. The modular approach also allows instructors to either pick one topic to provide breadth within a course or choose a set of multiple topics to provide a course with depth for a particular program of study. ERCs are good testbeds for such educational ideas because they are charged to expand and improve education at all member institutions in spite of barriers such as scheduling differences (e.g. quarters vs. semesters), new course approval procedures, etc.

The intended audience for all modules developed by the Smart Lighting ERC is students and faculty in electrical engineering, optical engineering, chemical engineering, materials science and engineering, physics, mechanical engineering, computer science, architectural engineering and architecture with a particular focus on new graduate students working on ERC research. Each module is designed to provide between six to eight contact hours of material. Thus, if seven to eight modules were combined together by an instructor the contact hour time would be equivalent to a complete college course. It should also be possible to adapt most modules for use by all other STEM students at the K$14 \&$ college level as classroom activities and/or outreach activities.

\section{EDUCATIONAL MODULE STRUCTURE}

Each module includes several specific documents that provide information to all users. The first document is a summary of the module that includes: title, a short description, reference materials and/or textbooks, list of goals/objectives and/or learning outcomes, anticipated audience, list of prerequisites and/or description of necessary background, and relationship to the "Illumineer" curriculum. This document could also include information needed for educational assessment with items such as identification of standards and learning assessment measures (i.e. ABET metrics). Often a detailed outline or calendar will be included that lists the order for topics to be covered.

The bulk of the module is of course the materials developed including lecture presentation slide sets, homework assignments, experiments, activities, projects, quizzes, etc. Suggestions for teaching methods should accompany these materials. For example, if recorded video lectures are available in a module then students could watch the lecture before a class meeting leaving class time for completing a problem-based-learning group activity. ${ }^{11,12}$ Module developers are strongly encouraged to provide video lectures to provide the maximum possible flexibility for content adopters and adapters and to encourage the use of the 'flipped classroom' that is driving so much positive innovation in STEM education. ${ }^{13}$

Probably the most important document is Instructor Reflection. Reflective statements about methods of instruction used, what worked and what did not work, and suggestions for improvement.

\section{NON-IMAGING OPTICS MODULE EXAMPLE AND USE IN A COURSE}

\subsection{Using the non-imaging optics module in a pilot course on illumination}

During the spring of 2012 a pilot optical engineering elective (Special Topics in Optics) course on Lighting and Illumination was taught at Rose-Hulman Institute of Technology. The pilot course had six students enrolled whose majors included optical engineering, physics, and electrical engineering. For a portion of the material covered in this course we used a module that we developed on the topic of non-imaging optics. Besides the non-imaging optics module content, the course included aspects of lighting design, human factors in lighting, and color science. It is our intention to further develop the material on color science into a module at a later date. Table 1 shows the summary document that briefly describes the non-imaging optics module and its content. Non-imaging optics is explicitly shown as an element of the "Illumineer" curriculum (see Fig. 1). Note that since this course is an elective for an ABET accredited optical engineering program it is important to identify which elements of the accreditation process are covered and these are included in the description. 
Table 1. Non-imaging optics module summary contents document

\section{Non-imaging optics educational module}

\section{Short Description}

Review of radiometry and photometry for illumination, types of sources used for illumination, etendue, concentration, edge ray design, introduction to design methods, lighting and illumination systems examples and case study.

\section{Prerequisites/Background}

Senior/Graduate Student Standing; introductory physics course covering basic optics including reflection and refraction; mathematics courses in differential equations. Introduction to radiometry and photometry would be useful.

\section{$\operatorname{Textbook}(\mathbf{s})$}

V. Arecchi, T. Messadi, and R. J. Koshel, Field Guide to Illumination Optics, SPIE Press (2007).

\section{Outcomes}

After a successful completion of this module the student will be able to:

- Understand the radiometric and photometric properties of light measurement

- Explain the importance of etendue in non-imaging optics

- Describe the difference between imaging and non-imaging optical systems

- Evaluate basic illumination systems designs using fundamental principles

Topics

A. Radiometry and Photometry

Terms and concepts; radiance, irradiance, luminance, illuminance, intensity; lighting and illumination measurement units.

\section{B. Sources}

Source modeling; source measurements; efficiency and efficacy; Types: daylight, LEDs, incandescent, high-intensity discharge, fluorescent.

C. Non-imaging optics

Etendue, concentration, skewness, introduction to design methods, edge ray design, CPC.

D. Illumination systems examples

Light transfer, fibers, lightpipes, mixing rods, displays. Evaluate systems based on illumination requirements. Case study of a particular lighting and illumination application.

\section{ABET Criteria}

This course/module primarily addresses ABET criteria a, c, e and k. 


\subsection{Non-imaging module sample materials and course format}

The course was mostly taught in a traditional lecture format although five class meetings were devoted to design evaluations, student presentations on lighting applications and a case study assignment. Sample slides from two lectures are shown in Figs. 2 and 3. Each of these two sample slides is provided to illustrate how specific course material relates to the course outcomes. The curves shown in Fig. 2 show the spectral response of three different standard sources along with the spectral response of a human observer viewing each source. Following this discussion, the students did an activity where they calculated and compared the luminous flux to the radiant flux emitted by each source. This exercise clearly illustrates how an observer is an integral part of the system and also provides the students with a better understanding of the relationship between lumen and Watt units and magnitudes of typical values for these quantities. It also opens up a discussion related to energy efficiency of lighting and illumination. Figure 3 shows a slide from the lecture on concentrators where parameters of a compound parabolic concentrator (CPC) are defined. Analyzing the geometry of the reflector using these definitions leads directly to relationships for the length and aperture of the concentrator. With this information a basic illumination system design can be evaluated.

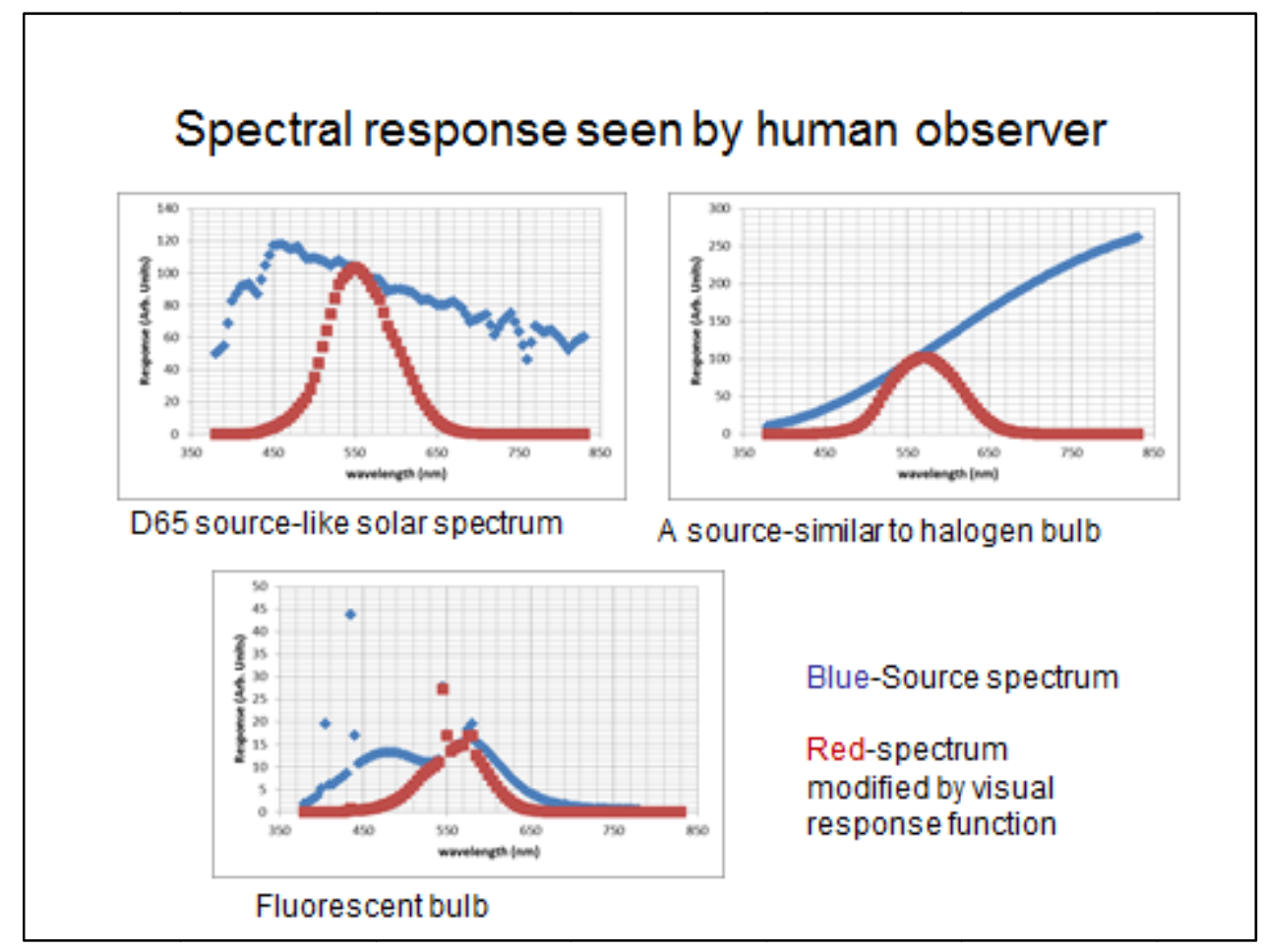

Figure 2. Example of the spectral response of a human observer viewing three different standard sources.

Additional material in this module includes: three homework assignments, one exam, one design evaluation problem, one case study, handouts of several papers from the literature, and references. Figure 4 shows a slide from a student's design evaluation report commenting on the basic concept of a CPC used as the starting point in a luminaire design. The case study relates to application of LED Street Lighting and arises from recent tests from several metropolitan regions. Students were asked to read the case and comment on the findings conveyed based on their non-imaging optics knowledge.

Although not part of the module, each student in the course researched an application of lighting and illumination and gave a short presentation to the class on their topic of interest. Topics included: Daylight Compensation, Lighting and Health, Light Pollution and Appropriate Outdoor Lighting, Design and Application of LED Light Guides, RGB LEDs, Backlighting LCDs. 


\section{Compound Parabolic Concentrator, CPC}

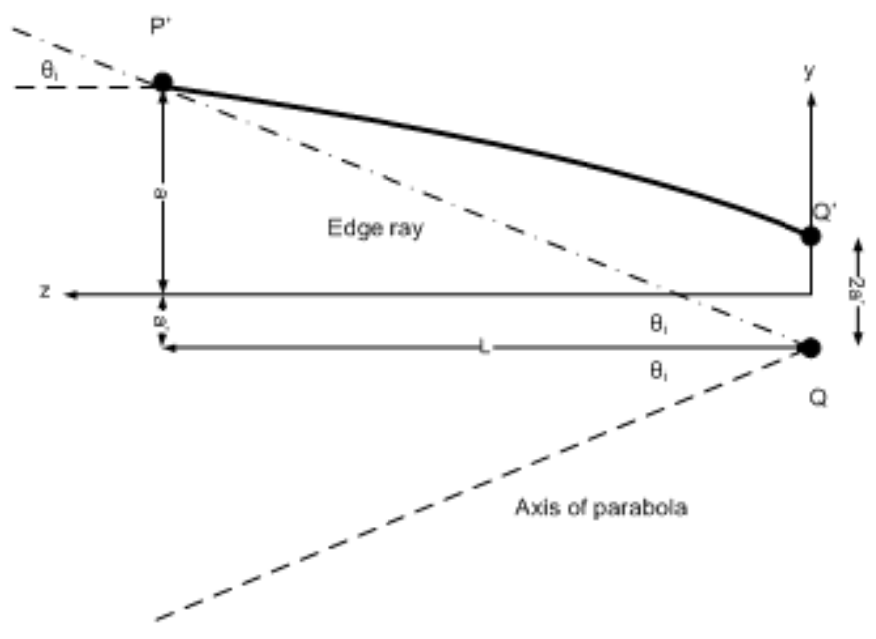

Figure 3. Drawing illustrating the geometry used in defining edge rays and angles a compound parabolic concentrator.

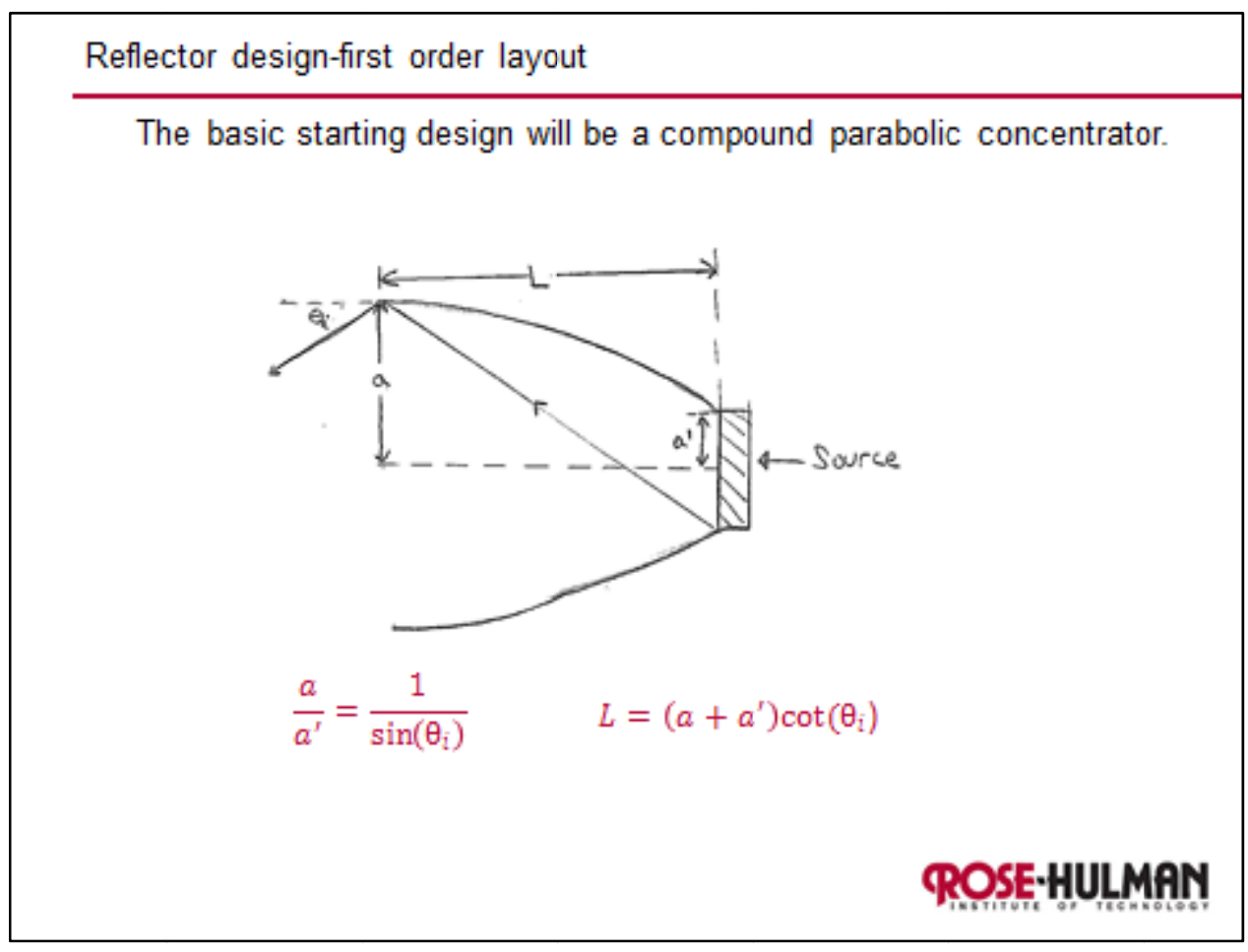

Figure 4. Example slide from a student's design evaluation report illustrating the basic concept of a CPC as the starting point of the design of a luminaire. 


\subsection{Instructor reflection on the use of the module and student assessment}

Reflecting on the module content, the material on radiometry and photometry could be broken out and expanded into a separate module. All of the students who took the course at Rose-Hulman had already taken a course that formally covered radiometry and photometry. Even with this background the students struggled with some concepts. This difficulty would be compounded for students who did not have any background in radiometry and photometry concepts. The module also needs more homework problems and a class activity on etendue, considering the importance of this concept to illumination. ${ }^{4}$ Using a flipped classroom approach might be a good way to further emphasize this topic. The case study assignment worked well but may benefit from developing a template for student's to follow since some instructors and students might not be familiar with this instructional method.

The next time this course is offered all lectures will be videoed so that they will be available for others to use as desired. Actually, the standard module development approach is to first teach the material as a pilot and then video the lectures the second time that the module is offered allowing for a cycle of refinement of the lecture material.

At the end of the spring term all students in the course completed a course evaluation as part of the regular assessment process at Rose-Hulman. In general, all students rated the course either excellent or very good. They also commented that the there was a lot of work for the amount of course credit received. Anecdotally, the students appreciated having a course in illumination. This was well expressed by one student who commented in the course evaluation, "good introduction to illumination and I think that is important because more and more illumination geared companies come to the career fair." Unfortunately, there were no specific student comments on the material associated with the non-imaging optics module. In the future a separate evaluation will be made immediately following the module activities.

The Department of Physics and Optical Engineering at Rose-Hulman uses an established assessment process for all optical engineering courses. ${ }^{14}$ One element of this assessment is a competency rating of course outcomes. Student competency of a specific outcome is accomplished by having the instructor identify one or more particular assignments (homework problem, exam question, quiz, class activity, lab report) that demonstrates the outcome and then count the number of students that successfully complete the assignment. Table 2 lists examples of questions (one homework problem and one exam question) used to evaluate student competency for the non-imaging optics module portion of the course. Competency ratings were completed for all outcomes specified in the module outline and all students achieved $100 \%$ competency.

Table 2. Sample questions used to evaluate student competency

\section{Homework question on photometry principles}

1. What fraction of the solar spectrum is contained in the visible part of the spectrum as viewed by a human observer? (Take the visible range to be $375 \mathrm{~nm}$ to $770 \mathrm{~nm}$ ).

Comment on the design of windows in buildings that must block solar radiant heat while admitting visible light.

\section{Exam question on imaging systems, non-imaging systems and etendue}

2. Give one example of an imaging system and one example of a non-imaging system used for illumination. Describe how you would compute the etendue for each system and comment on specific parameters one could trade-off in the design. 


\section{OTHER OUTREACH EDUCATIONAL ACTIVITIES RELATED TO SMART LIGHTING AND SUPPORT OF EDUCATIONAL MODULES}

Educational outreach by all partner institutions of the Smart Lighting ERC is accomplished through five categories of programs: 1) Undergraduate student research and design experiences, 2) Research experience for teachers, 3) Young scholars programs, 4) Pre-college programs, and 5) General community outreach. A central component of the outreach philosophy is the student mentoring hierarchy as illustrated in Fig. 5. Each student spends some time working with a younger student or providing support to an outreach program with younger students. Descriptions of two programs are given below.

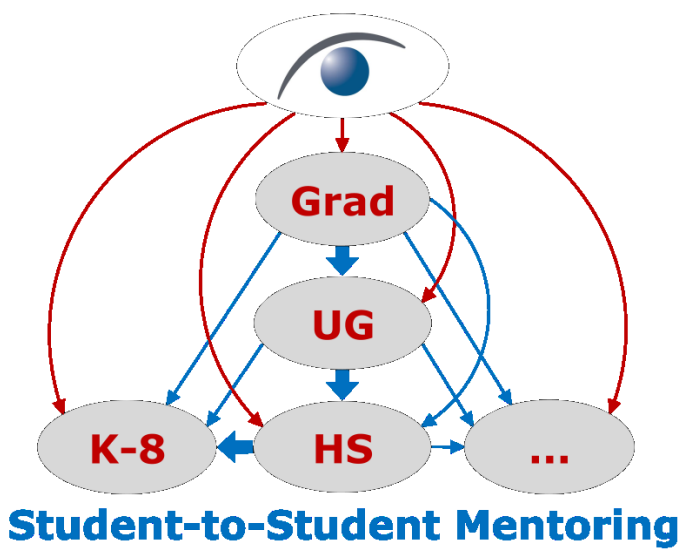

Figure 5. Smart Lighting ERC educational mentoring infrastructure.

Howard University has offered a six-week Young Scholar summer program for a diverse, under-represented population of 9-10 high school students with strong academic standing for past three summers (2010-2012). The six-week program incorporates basic electronics, soldering, computer networking, mobile studio and introduction to Smart Lighting technology. A sub-set of 3-4 students is identified to participate in a one week residential experience at Rensselaer's Smart Lighting Smart Power Smart System High School enrichment program prior to beginning their research at Howard University.

At Rose-Hulman groups of undergraduate students have been working on Smart Lighting research projects during the summer of 2011 and 2012. One optical engineering student from Norfolk State University participated each summer and in 2012 we had one Young Scholar. Besides their research project work each group developed a video presentation on some topic related to their research project. Five videos were completed in summer 2011 and five more are in preparation during summer 2012. Topics covered include, pn junctions, refractive index, light source characteristics, radiometry and photometry. The videos often include some type of demonstration. All completed video presentations are available for view over the internet ${ }^{15}$ and can be used as support to future educational modules using the studentsteaching-students approach.

\section{ACKNOWLEGEMENT}

This work was supported in part by the Engineering Research Centers Program of the National Science Foundation under NSF Cooperative Agreement No. EEC-0812056. 


\section{REFERENCES}

[1] http://smartlighting.rpi.edu/

[2] Julian, Warren G., "The Need for Lighting Education," Proc. SPIE Vol. 4588, 155-162 (2002).

[3] Ronen, Ram S. and Smith, R. Frank, "Shedding Light on the Subject: Introduction to Illumination Engineering and Design for Multi-Discipline Engineering Students," Proc. SPIE Vol. 2525, 628-634 (1995).

[4] Koshel, R. J. et. al., "Illumination system design in a project-based course," Proc. SPIE 7423, 742305 (2009).

[5] Hansen, Morten T. "IDEO CEO Tim Brown: T-Shaped Stars: The Backbone of IDEO's Collaborative Culture," Chief Executive, 21 January 2010, < http://chiefexecutive.net/ideo-ceo-tim-brown-t-shaped-stars-the-backbone-ofideoae \%E2\%84\%A2s-collaborative-culture> (10 June 2012).

[6] Goldschmid, B. and Goldschmid, M.L., 1973. "Modular education in higher education: a review" Higher Education 2 (1), 15-32 (1973).

[7] Shabani R., Massi L., Zhai L., Seal S., and Cho H.J. "Classroom modules for nanotechnology undergraduate education: development, implementation and evaluation" European Journal of Engineering Education 36 (2), 199210 (2011).

[8] Walker Constance E., "Educational System Engineering: The Hands-On Optics Module Development Experience" in Frontiers in Optics, OSA Technical Digest Series (Optical Society of America, 2005), paper FThD1.

[9] Pompea, S. M., Johnson, A., Arthurs, E., and Walker, C. E."Hands-On Optics: An Educational Initiative for Exploring Light and Color in After-School Programs, Museums, and Hands-On Science Centers", Proceedings, Ninth International Topical Meeting on Education and Training in Optics and Photonics, Marseille, France (2005).

[10] http://www.hands-on-optics.org

[11] Donnelly, J., Dischino, M., Hanes, F., and Massa, N., "Creating and using industry-based problem-based learning challenges in photonics: Lessons learned," Proc. ETOP (2009).

[12] http://www.pblprojects.org/

[13] Bergmann, Jonathan and Sams, Aaron, [FLIP YOUR CLASSROOM: Reach Every Student in Every Class Every Day], International Society for Technology in Education, (2012).

[14] Joenathan, C., Bunch, R. M., and Granieri, S. "Optical Engineering education with curriculum mapping for ABET accreditation", Proc. ETOP, 249 (2005).

[15] http://www.youtube.com/results?search_query=rose-hulman+smart+lighting 